\begin{tabular}{|c|c|c|}
\hline $\begin{array}{l}\text { PKS } \\
\text { PUBLIC } \\
\text { KNOLEDGE } \\
\text { DONLCTGE }\end{array}$ & $\begin{array}{c}\text { REVISTA DE GEOGRAFIA } \\
\text { (RECIFE) } \\
\text { Rttp://www. vistaufpe.br/revistageografia }\end{array}$ & 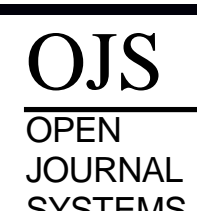 \\
\hline
\end{tabular}

\title{
O IMPERATIVO EPISTEMOLÓGICO DO ESPAÇO-TEMPO COMO DIMENSÃO ESTRUTURANTE DA REALIDADE
}

\author{
Avelar Araujo Santos Junior ${ }^{1}$ \\ ${ }^{\text {I} P r o g r a m a ~ d e ~ P o ́ s-G r a d u a c ̧ a ̃ o ~ e m ~ G e o g r a f i a . U F P E . E-m a i l: a v e l a r g e o @ h o t m a i l . c o m ~}$
}

Artigo recebido em 31/05/2018 e aceito em 12/11/2018

\begin{abstract}
RESUMO
O espaço e o tempo são categorias básicas da existência humana de maneira que se torna possível alcançar as suas qualidades objetivas a partir das práticas e processos materiais que constituem a vida social. Neste sentido, tomamos o espaço socialmente produzido como uma totalidade em contínuo movimento no qual o imbricamento entre múltiplas determinações políticas, econômicas, culturais, ambientais e ideológicas forma a complexidade das suas estruturas sociais. Na reprodução desse movimento dialético cada geração modifica as antigas circunstâncias recorrendo às rupturas e descontinuidades das estruturas precedentes, como também, dando vivacidade às relações de produção e às contradições que lhes são imanentes, tal como, a estruturação da sociedade em classes sociais distintas e, predominantemente, antagônicas. Tendo em vista essa complexidade anlítica, este artigo apresenta um conjunto de reflexões a respeito das possibilidades teóricas e metodológicas que circundam a dimensão espaço-tempo, desde a perspectiva epistemológica da Geografia.
\end{abstract}

Palavras-chave: espaço; tempo; metodologia; movimento.

\section{THE EPISTEMOLOGICAL IMPERATIVE OF SPACE-TIME AS A STRUCTURING DIMENSION OF REALITY}

\begin{abstract}
Space and time are basic categories of human existence so that it becomes possible to reach its objective qualities from the material practices and processes that make up social life. In this sense, we take socially produced space as a totality in continuous movement in which the intermingling of multiple political, economic, cultural, environmental and ideological determinations forms the complexity of its social structures. In the reproduction of this dialectical movement, each generation modifies the old circumstances by resorting to the ruptures and discontinuities of previous structures, as well as by giving vivacity to the relations of production and the contradictions that are immanent to them, such as the structuring of society in distinct social classes and, predominantly, antagonistic. Given this complexity, this article presents a set of reflections on the theoretical and methodological possibilities that surround the space-time dimension, from the epistemological perspective of Geography.
\end{abstract}

Keywords: space; time; methodology; movement. 


\section{INTRODUÇÃO}

Com o objetivo de dar fôlego a um dos debates centrais da ciência moderna, este artigo apresenta um conjunto de reflexões a respeito das possibilidades teóricas e metodológicas que circundam a dimensão espaço-tempo, desde a perspectiva epistemológica da Geografia. Como ponto de partida, tomamos como linha de entendimento a compreensão de Milton Santos a respeito do que ele denominou como uma "construção teórica para além do discurso", pois, para o professor somente a análise no plano dos discursos não permite a compreensão da realidade. Tal construção se fundamenta na busca por um sistema de instrumentos de análise proveniente de uma visão do real que nos possibilite "de um lado, intervir sobre a realidade como pensador e, de outro, reconstruir permanentemente aquilo que se chamará ou não de teoria" (1994, p. 86).

A essa construção teórica se soma a busca por apreender um objeto de estudo na complexidade das suas estruturas, dinâmicas e nexos internos, de modo que se desenvolva a reprodução ideal do movimento real do objeto pelo sujeito que pesquisa. Por este mesmo viés, dedicando-se aos sentidos epistemológicos da produção da ideia e da práxis, Ruy Moreira, ponderou:

A ideia que temos da coisa (o real) é o resultado da síntese de dois campos distintos: o campo visível e o campo intelectivo [...]. O campo sensível é o terreno dos sentidos (a visão, o tato, a audição etc.) e da percepção (as sensações reunidas numa única imagem em nossa mente). O campo intelectivo é o terreno do pensamento e dos conceitos. Esses dois campos se interligam através de nossas práticas [...]. Nossa relação com o mundo é, assim, uma práxis, isto é, nossa prática combinada com a nossa teoria numa interação dialética (MOREIRA, 2011a, p. 106).

Essas primeiras ponderações apontam para a pertinência da reflexão sobre os diferentes sentidos práticos que a reprodução ideal do objeto real pesquisa do pode assumir em função dos fundamentos teórico-metodológicos e das intencionalidades de uma investigação científica. $\mathrm{O}$ reconhecimento de tal pertinência nos desperta para a necessidade do discernimento entre essência e aparência do objeto, de modo que não se trata apenas de interpretar o mundo, mas também a transformá-lo (MARX e ENGELS, 1998). Tendo como objetivo alcançar a essência de uma problemática o pesquisador conduz sua investigação indo além da aparência fenomênica, imediata e empírica do objeto investigado (NETTO, 2011). Logo, as dimensões espaço-temporais dessa realidade, apesar de serem fugidias para as 
capacidades de apreensão do pesquisador, revelam os contínuos movimentos dialéticos que conformam a totalidade do real concreto na síntese entre a essência e aparência do objeto.

$\mathrm{Na}$ reprodução ideal da essência e, claro, no entendimento crítico da sua aparência, o pesquisador analisa o objeto acompanhando a gênese das suas estruturas e os processos que permitem a sua continuidade como prática social e histórica. Assim, com as atenções voltadas para o movimento histórico das práticas sociais se torna possível a articulação lógica das regularidades, tendências e contradições, entre outras variáveis engendradas na essência da realidade. Por essa perspectiva, buscamos discernir no âmbito dos fenômenos e processos em vias de aprofundamento o que é invariável no concreto-empírico, isto é, o que destacamos como essencial e regular para a compreensão do objeto e a identificação das suas tendências formativas.

\section{OS RIOS MUTANTES DO TEMPO-ESPAÇO}

Seguindo a reprodução histórica dos processos sociais se percebe o que Fernand Braudel designou de "rios mutantes do tempo" (1992, p. 76), com suas variações entre tempo social e tempo individual reproduzidos geograficamente. Os fluxos desses movimentos não teriam a mesmas direções, tão pouco as mesmas durações, de modo que os seus diferentes ritmos curtos ou longos possam ser distinguidos à proporção que se alcança uma consciência clara da pluralidade do tempo social que vai além das histórias particulares e das sucessões de eventos ou "fatos miúdos". Entretanto, a singularidade dos tempos dos indivíduos não pode ser negada, mas considerada como uma das dimensões constituídas e constituintes de todas as formas amplas da vida coletiva que, em função dos seus sentidos práticos na totalidade do real concreto, podem ser examinadas por meio de recortes conjunturais que particularizam os diferentes tempos da história. Deste modo, provoca-nos o autor: "trata-se, para quem quer compreender o mundo, de definir uma hierarquia de forças, de correntes, de movimentos particulares, depois, apreender de novo uma constelação de conjunto" (BRAUDEL, 1992, p. 54). Contudo, sobre a eficácia contemporânea da proposta de Braudel de um tempo longo e de um tempo curto, Santos (1996, p. 212), chamou a atenção para a necessidade de correlacionála a outra ideia que também expressa dois termos opostos e inversamente proporcionais, ou seja, "a noção de um tempo rápido ao qual se antepõe um tempo lento" (grifos originais). De tal modo que essas denominações de quantidades e qualidades relativas corresponderiam ao tempo das ações sociais que animam os objetos técnicos em múltiplos graus e modalidades de combinações de tempos presentes. 
Por conseguinte, depreendemos que as regularidades, tendências e contradições da realidade transitam pelos nexos estruturais de processos historicamente constituídos e espacialmente objetivados por sujeitos sociais que, a despeito das suas intencionalidades individuais, têm de corresponder às expectativas dos grupos de interesse ou coletividades dos quais, socialmente, fazem parte.

As relações sociais são carregadas de intencionalidades. Estas se expressam nos objetivos, crenças, pontos de vista e ações de indivíduos, grupos, classes, povos, nações. Geralmente, por meio delas realiza-se a materialização dos indivíduos no espaço. Para tanto, promovem uma fragmentação do espaço mediante sua apropriação/dominação por uma dada relação social (RAMOS FILHO, 2008a, p. 34).

Atentos ao curso histórico desses processos espacialmente objetivados, vejamos outras considerações que nos auxiliam na reflexão sobre a complexidade analítica da pesquisa geográfica. Para Hobsbawm, por exemplo, "ser membro de uma comunidade humana é situarse em relação ao seu passado (ou da comunidade), ainda que apenas para rejeitá-lo" (1998, p. 17). Na sua perspectiva, o passado, além de ser uma dimensão permanente da consciência humana referente aos eventos registrados na memória de um indivíduo, é também um elemento das instituições, valores e outros padrões da sociedade humana. O desafio metodológico sublinhado pelo historiador se encontra na análise da natureza do "sentido do passado" que abarca os padrões e mecanismos gerais da mudança histórica, e, particularmente, das transformações das sociedades humanas durante os últimos séculos de ampliação do modo de produção capitalista.

Voltando a sua mirada para o futuro, Hobsbawn (1998, p. 46) recomendou a busca pela compreensão das "tendências sociais" por intermédio da compreensão dos rumos do desenvolvimento social, sem perder de vista que passado, presente e futuro formam um continuиm. Esta orientação, só aparentemente simples, resulta do entendimento de que a maior parte da ação humana consciente - para ele baseada em aprendizado, memória e experiência - estabelece um vasto mecanismo desenvolvido para comparar e discernir os vínculos entre passado, presente e futuro. Fundamentando-se numa concepção materialista da história, Hobsbawm, sugeriu a seguinte estrutura analítica para a análise da história: 
Essa estrutura deve estar baseada no único elemento observável e objetivo de mudança direcional nos assuntos humanos - a capacidade persistente e crescente da espécie humana de controlar as forças da natureza por meio do trabalho manual e mental, da tecnologia e da organização da produção (HOBSBAWM, 1998, p. 39).

Nesta direção, também podemos considerar o que Marx e Engels (1998, p. 21) expuseram sobre o que eles consideraram como o primeiro fato histórico que pressupõe toda a existência humana - a produção dos meios que permitem satisfazer as necessidades da vida material de modo que os seres humanos possam viver para, enfim, poder fazer a história. Satisfeitas essas necessidades iniciais se dá o primeiro "ato histórico" com a produção de novas necessidades. Já um terceiro nível de relação que intervém diretamente no "desenvolvimento histórico" se manifesta na reprodução biológica dos seres humanos na medida em que a família passa a representar a unidade sociológica de onde emanam novas necessidades, gerando assim novas relações sociais e o aumento da população que, por sua vez, suscitam novas e ampliadas necessidades. Os autores ressaltaram que esses aspectos da atividade social coexistem desde os primeiros momentos da história humana, de maneira que integram os modos de produção desenvolvidos pelas forças produtivas de suas épocas.

Produzir a vida, tanto a sua própria vida pelo trabalho, quanto a dos outros pela procriação, nos parece, portanto, a partir de agora, como uma dupla relação: por um lado como uma relação natural, por outro como uma relação social - social no sentido em que estende com isso a ação conjugada de vários indivíduos, sejam quais forem as suas condições, forma e objetivos (MARX e ENGELS, 1998, p. 23)

O "ser social”, por consequência, seria concebido pelas relações sociais de produção a que pertencem, denominado por Reis (1996) como um "ser relacional" situado, concretamente, num tempo e num lugar. Nesta perspectiva, a realidade histórica se torna uma "estrutura em processo" na qual a sua abordagem precisa reconstruir a dialética de sua sincronia e diacronia. Assim sendo, verifiquemos a seguinte perspectiva marxiana desse autor:

A ontologia marxista é "relacional" - o ser social não é uma "coisa" mas relações históricas determinadas. Ao mesmo tempo que absolutamente historicizado, este ser conservaria um resíduo intemporal, presente em todas as formações sociais e inultrapassável: a relação insuperável entre homem e natureza. Mas esta relação trans-histórica muda permanentemente de qualidade nos diferentes lugares e épocas (REIS, 1996, p. 43). 
Essa concepção relacional toma como base explicativa o desenvolvimento da produção material da vida humana por meio da sucessão de diferentes gerações, "cada uma das quais explora os materiais, os capitais e as forças produtivas que lhes são transmitidas pelas gerações precedentes" (MARX e ENGELS, 1998, p. 46-47). Cada geração prossegue com o modo de atividade que lhe é legado, mas no campo de novas circunstâncias transformadoras, especialmente, no que se refere aos avanços das forças produtivas.

$\mathrm{Na}$ reprodução desse movimento dialético cada geração modifica as antigas circunstâncias recorrendo às rupturas e descontinuidades das estruturas precedentes, como também, dando vivacidade às relações de produção e às contradições que lhes são imanentes, tal como, a estruturação da sociedade em classes sociais distintas e, predominantemente, antagônicas. Não foi por acaso que no prefácio à edição alemã de 1883 do Manifesto Comunista, Engels, lembrou da seguinte maneira um dos axiomas desenvolvidos por Marx:

O pensamento dominante e essencial do Manifesto, isto é, que produção econômica e a estrutura social que necessariamente decorre dela constituem em cada época a base da história política e intelectual dessa época; que, por conseguinte (desde a dissolução do regime primitivo da propriedade comum da terra), toda a História tem sido uma história de lutas de classes, de lutas entre as classes exploradas e as classes exploradoras, entre as classes dominantes e as classes dominadas (MARX e ENGELS, 1988, p. 67).

Portanto, com enfoque na dimensão material do espaço composta pelos objetos fixos (naturais ou criados pelos seres humanos) e ações (fluxos) que determinam a espacialização via a temporalização prática, Santos (1994), concebeu o espaço para além da sua materialidade empírica e do domínio da necessidade, de tal modo que ele observa: "a vida não é um produto da Técnica, mas da Política, a ação que dá sentido à materialidade" (SANTOS, 1994, p. 17). O tempo cotidiano compartilhado é percebido como um tempo plural, "um tempo dentro do tempo", correspondendo assim a uma variável analítica que demonstra o movimento das contradições que entrelaçam os próprios objetos fixos e ações. É com base nessa dimensão política do espaço que Milton Santos faz a seguinte distinção:

O território são formas, mas o território usado são objetos e ações, sinônimo de espaço humano, espaço habitado. Mesmo a análise da fluidez posta a serviço da competitividade, que hoje rege as relações econômicas, passa por aí. De um lado, temos uma fluidez virtual, porque a real vem das ações humanas, que são cada vez mais ações informadas, ações normatizadas (SANTOS, 1994, p. 16). 
Outros elementos para a análise totalizante do movimento da história se encontram no esforço de desenvolver alternativas de representação do tempo que superem a visão unilinear de irreversibilidade de estruturas sociais. A perseguição dos ritmos e fluxos das transformações historicamente produzidas e espacialmente objetivadas nos provoca a explorar recursos discursivos que abrangem a temporalidade de modo multilinear e transversal, relativizando experiências e formas de apreensão que constituem a consciência humana sobre o tempo nas mais diversas condições ambientais, sociais e culturais.

Neste movimento, o desenvolver de narrativas sobre o passado, isto é, a memória, apresenta-se como uma capacidade humana que potencializa a variabilidade das representações que reconfiguram singularidades no tempo e no espaço. Explorando essa capacidade humana de tornar presente ideias e impressões, Kosik (2002), compreendeu a memória como uma estrutura histórica ativa e um modo de organização da consciência humana, enquanto conhecimento que, por meio da práxis, integra continuamente o presente.

$\mathrm{Na}$ memória humana o passado se faz presente e assim supera a transitoriedade, porque o passado mesmo é para o homem uma coisa que ele não deixa para trás como algo desnecessário; é algo que entra no seu presente de modo constitutivo, como natureza humana que se cria e se forma (KOSIK, 2002, p. 150).

Ao encaminhar suas observações sobre o tema da narrativa memorial nos domínios da etnografia histórica, Arruti (2006), salientou a necessidade de se abordar a memória por vieses que vão além do subjetivismo e do objetivismo que a postulam de maneira dicotômica, respectivamente, como tema mítico ou como simples fonte alternativa de reconstituição do passado. Por efeito, tão relevante quanto acessar as histórias de vida e os relatos de domínio coletivo, torna-se importante discernir as formas pelas quais o presente se relaciona com o passado, tanto quanto, conhecer a multiplicidade das perspectivas que substancializam as interpretações conflitantes alusivas aos eventos do passado. De tal modo, a memória passa a ser compreendida como uma perspectiva que possibilita "destextualizar" os documentos escritos, uma vez que também adverte sobre as incertezas, contradições e escolhas dos atores concretos.

Ao relevar a importância de se recuperar a localização de "antigas marcas mnemoterritoriais", Arruti (2006), apontou caminhos interpretativos favoráveis à percepção de sistemas sociais que desenvolvem formas particulares de produção, organização e representação dos espaços, notadamente, de territórios. Como condicionante dos "modos de 
lembrar" e de narrar as sequências dos fatos no espaço, o território, acaba assumindo um sentido de suporte e matéria da memória social da qual podem ser elucidados, entre outros elementos, os seus modos de produção e transmissão, as formas e estratégias de objetivação da relação com o passado, os topos que marcam a passagem do tempo e registram a existência de personagens importantes, os interesses sociais e políticos da recordação, as modalidades narrativas e os conteúdos disponibilizados ou silenciados pelos seus narradores.

Certamente, atentar-se a esse sentido multidimensional do território, mais do que instigante, poderá ser útil na análise empírica dos arranjos espaciais e temporais das pesquisas geográficas em questão. Afinal, como ponderou Milton Santos, o espaço pode ser apreendido como uma condição da realização concreta do modo de produção e de seus momentos, uma vez que "testemunha um momento [...] de um modo de produção pela memória do espaço construído, das coisas fixadas na paisagem criada" (SANTOS, 1978, p. 138). De tal maneira que os processos que determinam um modo de produção novo ou um novo momento de um mesmo modo de produção, tanto prescindem das formas duráveis e preexistentes do espaço, quanto criam novas formas espaciais consoantes à renovação dos objetivos das forças e relações produtivas em desenvolvimento. Para representar este caráter testemunhal do espaço Santos (1978) definiu da seguinte maneira a categoria geográfica que, apesar de ser relativa à reprodução social, toma emprestado o vocábulo geomorfológico de "rugosidade":

As rugosidades são o espaço construído, o tempo histórico que se transformou em paisagem, incorporado ao espaço. As rugosidades nos oferecem, mesmo sem tradução imediata, restos de uma divisão de trabalho internacional, manifestada localmente por combinações particulares do capital, das técnicas e dos trabalhos utilizados. Assim, o espaço, espaçopaisagem, é o testemunho de um momento de um modo de produção nestas suas manifestações concretas, o testemunho de um momento do mundo (SANTOS, 1978, p. 138).

O espaço e o tempo são categorias básicas da existência humana de maneira que se torna possível alcançar as suas qualidades objetivas a partir das práticas e processos materiais que constituem a vida social. Segundo o geógrafo é no bojo das práticas da reprodução social que o tempo social e o espaço social estão construídos de maneira diferencial, também variando geográfica e historicamente os seus conceitos e sentidos. Invariavelmente, essas diferenças de representações do espaço e do tempo afetam as formas de interpretação e atuação do/no mundo, mais uma vez, devendo-se considerar os arranjos das experiências individuais e coletivas. 
Como o capitalismo foi (e continua a ser) um modo de produção revolucionário em que as práticas e processos materiais de reprodução social se encontram em permanente mudança, segue-se que tanto as qualidades objetivas como os significados do tempo e do espaço também se modificam. Por outro lado, se o avanço do conhecimento (científico, técnico, administrativo, burocrático e racional) é vital para o progresso da produção e do consumo capitalistas, as mudanças do nosso aparato conceitual (incluindo representações do espaço e do tempo) podem ter consequências materiais para a organização da vida diária (HARVEY, 1992, p. 189).

À primeira vista essas ideias parecem redundantes face ao que já expusemos em relação ao tempo e espaço como categorias de análise, mas agora acrescentamos aos desdobramentos das nossas reflexões a perspectiva de síntese relacional da dimensão espaço-tempo -, objetivando a articulação dos instrumentos teórico-metodológicos da Geografia. Nesta direção, outros pensamentos de David Harvey chamam a nossa atenção para os discursos contemporâneos sobre o espaço-tempo como um nexo mediador entre o dinamismo do desenvolvimento histórico-geográfico do capitalismo e os processos de produção cultural e de transformação ideológica.

No plano das ideologias, David Harvey situa a modernidade como um processo de desorganização constante dos ritmos temporais e espaciais no contexto da cultura capitalista. O desafio posto aos modernistas (para Harvey, os que se debruçam sobre as experiências do espaço e do tempo da atualidade) seria o de produzir novos sentidos para o espaço e o tempo num mundo do efêmero, do transitório, do acelerado e do fragmentado, sobretudo, a partir do modelo fordista das relações de produção. Os novos discursos surgidos no mundo ocidental nas últimas décadas têm configurado uma condição pós-moderna da acumulação capitalista que, por meio da compressão espaço-temporal da acumulação flexível pós-fordista, vem estabelecendo a superação das barreiras espaciais e o aniquilamento do espaço pelo tempo. A questão posta é que, mesmo não sendo um fenômeno novo na aceleração dos ritmos da vida moderna, tal compressão, que para Harvey deveria ser relativa a um estado de coisas precedentes, tem determinado impactos desorientadores nas práticas econômico-políticas, no equilíbrio do poder de classe e na vida cultural e social.

Se há algum sentido na história, há que descobri-lo e defini-lo a partir de dentro do turbilhão da mudança, um turbilhão que afeta tanto os termos da discussão como o que está sendo discutido. A modernidade, por conseguinte, não apenas envolve uma implacável ruptura com todas e quaisquer condições históricas precedentes, como é caracterizada por um interminável processo de rupturas e fragmentações internas inerentes (HARVEY, 1992, p. 22). 
Torna-se necessário relativizar esses argumentos de Harvey referentes ao que ele denomina como uma inquietude da atual fase do desenvolvimento econômico, politico e cultural, especialmente no Ocidente. Harvey aponta como elemento analítico o arranjo dos vínculos do efêmero e do veloz com o eterno e o imutável, objetivando o exame dessa aviltada condição transitória das coisas que, para o geógrafo, tem dificultado a conservação do sentido de continuidade histórica. Os horizontes temporais têm sido reduzidos ao presente como única possibilidade de existência, estabelecendo o domínio simultâneo do tempo e do espaço (e, por consequência, do dinheiro) como elemento substancial do poder social em disputa nas economias monetárias, em geral, e na sociedade capitalista, em particular. Algo próximo do que, Carlos (2007), interpreta como a produção do “espaço amnésico”, isto é:

Um espaço sem referências e inóspito à vida, porque limita e restringe as modalidades do uso. Nesse contexto, o uso, que se revela no espaço como modo da reprodução da vida através dos modos apropriação enquanto duração, associa-se às regras de um espaço normatizado e homogêneo (CARLOS, 2007, p. 58).

$\mathrm{Na}$ correlação entre as diferentes periodizações experimentadas por David Harvey e Milton Santos para acompanhar os "ritmos" e "fluxos" da vida contemporânea - a propósito, recomendados por Moreira (1982, p. 68) como os maiores colaboradores em relação à dialética do espaço -, entendemos que o geógrafo brasileiro aborda os processos sociais da atualidade problematizando o que ele denominou de "a era da globalização" (SANTOS, 2002, p. 153). Segundo a sua interpretação sistêmica da redefinição de cada coisa em relação ao todo planetário, a nossa época está sendo marcada pela multiplicação incessante da produção material de objetos e, no sentido imaterial, pela infinidade de relações carregadas de ideologias e simbolismos que passamos a estabelecer com estes objetos nos domínios do território e do cotidiano.

À continuação, Santos afirmou que este período vem sendo abalizado por uma técnica e uma política planetárias que sugerem uma ideia de realidade histórica unitária do mundo na qual se concretiza a tendência hegemônica do lucro em escala global, a despeito das diversidades sociais e culturais que subjazem a esse suposto sentido unitário. Consequentemente, a globalização econômico-financeira tem engendrado a emergência de um mercado em contínua ampliação global que impõe tendências políticas e programas econômicos dominantes, especialmente, nos países periféricos em relação às economias centrais. Porém, à luz das dialéticas da vida nos lugares, dão-se as condições intelectuais, 
objetivas e materiais que, a exemplo das técnicas de informação atuais, aplicadas de forma democrática e engajada, elucidam sinais indicativos de uma fase de transição para um novo período histórico na construção de um mundo mais humano e fundamentado numa nova política (SANTOS, 2002).

Em observação mais próxima do nosso presente, Milton Santos (2008), ao sinalizar as possibilidades da necessária transição para um verdadeiro período popular da história, isto é, uma "outra globalização" que parta de um pensamento único para a consciência universal, identificou os seguintes fatores que contribuem para explicar o que ele qualifica de "arquitetura da globalização":

A unicidade das técnicas, a convergência dos momentos, a cognoscibilidade do planeta e a existência de um motor único na história, representado pela mais-valia globalizada. Um mercado global utilizando esse sistema de técnicas avançadas resulta nessa globalização perversa. Isso poderia ser diferente se seu uso político fosse outro. Esse é o debate central, o único que nos permite ter a esperança de utilizar o sistema técnico contemporâneo a partir de outras formas de ação (SANTOS, 2008, p. 24).

Portanto, para Santos (2008), os sistemas de técnicas que, amplamente, instaura o processo de internacionalização do mundo capitalista mediante a globalização, realizam a combinação entre trabalho e as escolhas dos seus momentos e lugares de uso que, por seu turno, caracterizam a história nos seus diferentes contextos e períodos. A novidade dos tempos da globalização é que, pela primeira vez na história da humanidade, uma unicidade do tempo e das técnicas, especialmente as informacionais, permite a ampliação de um sistema de finanças universal que impõe a mais-valia globalizada alavancando sobremaneira a apropriação privada do trabalho social e dos meios de produção. No entanto, ao questionar a quem favorece essa mais-valia somada à aceleração da história e à convergência dos momentos no "tempo real" (ou unicidade do tempo), advertiu Milton Santos:

A história é comandada pelos grandes atores desse tempo real, que são, ao mesmo tempo, os donos da velocidade e os autores do discurso ideológico. Os homens não são igualmente atores desse tempo real. Fisicamente, isto é, potencialmente, ele existe para todos. Mas efetivamente, isto é, socialmente, ele é excludente e assegura exclusividades, ou pelo menos, privilégios de uso (SANTOS, 2008, p. 28). 


\section{CONSIDERAÇÕES FINAIS}

Diante do exposto, tomamos o espaço socialmente produzido como uma totalidade em contínuo movimento no qual o imbricamento entre múltiplas determinações políticas, econômicas, culturais, ambientais e ideológicas forma a complexidade das suas estruturas sociais. Também já percebemos que a análise histórica do espaço, ou geográfica da história, implica na busca pelo entendimento da formação socioespacial de uma sociedade a partir das mudanças conjunturais que se sucedem, dialeticamente, no sentido de superar a estrutura preexistente. Ou seja, de acordo com a transitoriedade dos modos de produção que lhes são historicamente correspondentes, sobretudo, no tocante às contradições que envolvem a expansão das forças produtivas face às mudanças nas relações de produção.

Vale lembrar que, segundo Moreira (2012), uma formação socioespacial mantém organicidade com a formação econômico-social na medida em que é organizada pelo modo de produção hegemônico através dos conflitos decorrentes das relações que aglutinam interesses mobilizadores, seja do todo da sociedade civil (no âmbito das classes sociais), seja do todo da sociedade política (nas camadas jurídico-políticas e ideológico-culturais). A partir da correlação entre essas forças sociais, o todo da infraestrutura e da superestrutura passa a ser regido conjunturalmente por combinações de estrutura e conjuntura que as convertem também numa formação socioespacial. Assim, para o professor, tal correlação estrutura-conjuntura é compreendida como um "vetor de comando" do processo de reprodução da sociedade, de modo que o arranjo espacial (MOREIRA, 2012), na qualidade de elemento de permanência que orienta o continuum dessa reprodutividade, acaba sendo a expressão das formações econômico-social e socioespacial.

Uma vez que a estrutura da formação econômico-social determina a estrutura do arranjo espacial conjuntural, é esse arranjo espacial conjuntural que comanda a estrutura em seus movimentos, processos e formas no tempo. O espaço aparece, assim, nos termos do seu arranjo como a expressão do todo articulado da estrutura-conjuntura ao mesmo tempo que como termo da mediação da realização do todo movimento contraditório da formação econômico-social. Razão pela qual, em sua interação dialética, é ele a forma real de existência da sociedade em cada tempo, fazendo dela uma realidade histórico-concreta efetivamente (MOREIRA, 2012, p. 109).

Podemos distinguir umas das bases desse pensamento de Ruy Moreira na sua leitura lefebvriana do espaço como categoria estruturante que comanda a reprodução das relações de produção uma vez que se torna uma condição da própria reprodução da sociedade humana. Tal centralidade analítica advém da dinâmica na qual a produção do espaço coordena e reúne 
aspectos práticos da estrutura global da sociedade, ao passo em que o espaço social intervém, ao mesmo tempo em que é efeito, causa e razão do modo de produção que realiza (LEFEBVRE, 2006). É nesta perspectiva, por exemplo, que entendemos a abordagem histórico-estrutural desenvolvida por Moreira (2011b), no livro "Sociedade e Espaço Geográfico no Brasil”, ao tratar de maneira analítica e descritiva, das determinações históricas da estrutura social brasileira e do seu arranjo espacial, compreendido, pois, como uma totalidade de objetos localizados e distribuídos no espaço em cada tempo. A propósito, não foi por casualidade que o autor começou a sua explanação sobre os fundamentos e fundações da realidade estrutural brasileira desta maneira:

A forma da organização geográfica da sociedade brasileira atual tem sua origem na disponibilização que fatia o espaço indígena em grandes domínios de propriedade, instituindo a colonização portuguesa à base de um poder do colono a um só tempo fundiário, territorial e político. Terra, território e senhorio político, num tripé, formam desde então, a estrutura do espaço sobre a qual se ergue a sociedade no Brasil (MOREIRA, 2011b, p. 11).

Buscando robustecer nosso entendimento sobre esse sentido do espaço como história e estrutura, mais uma vez, Santos (1978, p. 152) nos é esclarecedor: “Através do espaço, a história se torna, ela própria, estrutura, estrutura em formas. E tais formas, como formasconteúdo, influenciam o curso da história, pois, elas participam da dialética global da sociedade". Além disso, para Santos (2006), na tentativa de tornar o tempo e espaço mutuamente includentes, deve-se buscar também a empiricização do tempo:

Tempo, espaço e mundo são realidades históricas, que devem ser mutuamente conversíveis, se a nossa preocupação epistemológica é totalizadora. Em qualquer momento, o ponto de partida é a sociedade humana em processo, isto é, realizando-se. Essa realização se dá sobre uma base material: o espaço e seu uso; o tempo e seu uso; a materialidade e suas diversas formas; as ações e suas diversas feições (SANTOS, 2006, p. 36).

Servindo para "desvendar máscaras sociais", tal como preconizou Moreira (1982, p. 35) no sentido de revelar as relações de classes que determinam os arranjos espaciais, a Geografia dispõe de subsídios teórico-metodológicos úteis para a análise da reprodução ampliada da lógica do modo de produção hegemônico e seus mecanismos de controle da sociedade, por sinal, vendados pelas tais máscaras sociais dos nossos tempos. Reconhecendo a profundidade analítica do tema proposto, esperamos que este artigo possa contribuir para uma maior notoriedade das possibilidades teórico-metodológicas suscitadas pela dimensão 
espaço-tempo, sobretudo no âmbito da ciência geográfica. Assim, mais do que uma mera oportunidade, lançar o olhar sobre a dinâmica espaço-tempo torna-se um imperativo para o geógrafo.

\section{REFERÊNCIAS}

ARRUTI, José Maurício Andion. Mocambo: antropologia e história do processo de formação quilombola. Bauru: Edusc, 2006.

BRAUDEL, Fernand. Escritos sobre a História. $2^{a}$ ed. São Paulo: Perspectiva, 1992.

CARLOS, Ana Fani Alessandri. O Espaço Urbano: Novos Escritos sobre a Cidade. São Paulo: FFLCH, 2007.

HARVEY, David. A condição pós-moderna. Uma pesquisa sobre as origens da mudança cultural. São Paulo: Edições Loyola, 1992.

HOBSBAWM, Eric. Sobre história. São Paulo: Companhia das Letras, 1998.

KOSIK, Karel. Dialética do concreto. $7^{\text {a }}$ ed. Rio de Janeiro: Paz e Terra, 2002.

LEFEBVRE, Henri. A produção do espaço. Trad. Doralice Barros Pereira e Sérgio Martins (do original: La production de l'espace. 4e éd. Paris: Éditions, Anthropos, 2000). Primeira versão: $\quad$ início $2006 . \quad$ Disponível em:< http://www.mom.arq.ufmg.br/mom/arq_interface/1a_aula/A_producao_do_espaco.pdf>. Acesso em: 13 jul. 2014.

MARX, Karl; ENGELS, Friedrich. Manifesto do partido comunista. $7^{\mathbf{a}}$ ed. São Paulo: Global, 1988.

MARX, Karl; ENGELS, Friedrich. A ideologia alemã. São Paulo: Martins Fontes, 1998.

MOREIRA, Ruy. A geografia serve para desvendar máscaras sociais. In: MOREIRA, Ruy (org.). Geografia: teoria e crítica. O saber posto em questão. Petrópolis: Vozes, 1982.

MOREIRA, Ruy. Pensar e ser em geografia: ensaios de história, epistemologia e ontologia do espaço geográfico. $2^{\mathbf{a}}$ ed. São Paulo: Contexto, 2011a.

MOREIRA, Ruy. Sociedade e espaço geográfico no Brasil: constituição e problemas de relação. São Paulo: Contexto, 2011 b.

MOREIRA, Ruy. Geografia e práxis: a presença do espaço na teoria e na prática geográficas. São Paulo: Contexto, 2012.

NETTO, José Paulo. Introdução ao estudo do método de Marx. $1^{\text {a }}$ ed. - São Paulo: Expressão popular, 2011. 
RAMOS FILHO, Eraldo da Silva. De pobre e sem-terra a pobre com-terra e sem-sossego: territorialização e territorialidades da reforma agrária de mercado (1998-2006). In: Fernandes, Bernardo Mançano; Medeiros, Leonilde e Paulilo, Maria (coords.). Lutas camponesas contemporâneas: condições dilemas e conquistas. São Paulo: UNESP: 2008b, p. 247-278. REIS, José Carlos. A história, entre a filosofia e a ciência. São Paulo: Ática, 1996.

SANTOS, Milton. Por uma geografia nova: da crítica da geografia a uma geografia crítica. São Paulo: HUCITEC/EDUSP, 1978.

SANTOS, Milton. Técnica, espaço, tempo: globalização e meio técnico-científicoinformacional. São Paulo: Hucitec, 1994.

SANTOS, Milton. A Natureza do Espaço: Técnica e Tempo, Razão e Emoção. São Paulo: Hucitec, 1996.

SANTOS, Milton. O País distorcido: O Brasil, a globalização e a cidadania. São Paulo: Publifolha, 2002.

SANTOS, Milton. A Natureza do Espaço: Técnica e Tempo, Razão e Emoção. - 4. ed. 2. reimpr. - São Paulo: Editora da Universidade de São Paulo, 2006.

SANTOS, Milton. Por uma outra globalização: do pensamento único à consciência universal. Rio de Janeiro: Record, 2008. 